\title{
A EXPERIÊNCIA URBANA STEAMPUNK: ENTRE A LITERATURA DE FICÇÃO CIENTÍFICA E AS RUAS DO BRASIL
}

\author{
POR \\ Éverly Pegoraro \\ Universidade Estadual do Centro-Oeste (Unicentro)
}

"E se tivesse sido diferente?". Quem nunca fez essa pergunta, que atire a primeira pedra. Os jovens que participam do steampunk não atiram pedras, mas performatizam uma visão de mundo e lançam reflexões a partir dessa inquietante pergunta. Fruto da ficção científica contemporânea, em seu subgênero cyberpunk, pode-se dizer que o steampunk salta das páginas da literatura que lhe deu origem e ganha forma em uma cultura urbana juvenil que conquista cada vez mais adeptos mundo afora.

O steampunk é uma cultura urbana que parte de uma premissa retrofuturista. A mistura entre elementos do passado (numa caracterização retro) com tecnologia futurista é o seu ponto de partida. Os contextos históricos predominantes (mas não exclusivos) do universo steampunk são a Era Vitoriana e a Revolução Industrial. As histórias se centram numa suposta Era do Vapor Steampunk, na qual a tecnologia a vapor teria sido o ápice do desenvolvimento social. Para isso, as criações (re)inventam as narrativas históricas como são conhecidas, combinando personagens, fatos e fiç̧ões, reelaborando-os em diferentes épocas e contextos. Em outros casos, simplesmente inventam personagens contextualizados no século XIX, mas reelaborados com características futuristas. O grande objetivo é lançar o questionamento "e se tivesse sido diferente?" A pergunta do steampunk não busca simples especulações, mas lança reflexões sobre as escolhas humanas e o rumo que elas dão ao convívio social.

O steampunk reflete uma característica típica da sociedade atual, que é o fascínio pelo passado. Por outro lado, afasta-se da simples melancolia por um tempo perdido, pois suas criações trabalham com um hibridismo entre passado, presente e futuro. Essa cultura retrofuturista aponta profundas alterações perceptivas da experiência espaçotemporal contemporânea.

Este artigo objetivo refletir como o steampunk, através das criações na literatura e das performances dos participantes da cultura juvenil, "sente" o espaço urbano e estabelece relações temporais que ultrapassam a concepção linear de tempo tal qual é conhecida. As experiências corporais em seu uso do espaço urbano agenciam (Deleuze e Guattari) 
comportamentos, interações e formas de visualizar a cidade. Para isso, relaciona-se a literatura retrofuturista steampunk (através da primeira coletânea de contos do gênero lançada no Brasil) com as performances de um grupo de steamers (como são conhecidos os participantes do steampunk) brasileiros, localizado em Curitiba, capital do Paraná, estado da região Sul do Brasil.

\section{RETROFUTURISMO: UMA TRANSGRESSÃO TEMPORAL NEGOCIADA}

“Como consertar este presente histórico insuportável a olho nu?”, questiona Jameson (“Progress Versus Utopia” 152), já que, na sua concepção, o passado está morto e o futuro é irrelevante ou inimaginável. Para ele, a ficção científica cria uma estrutura temporal que desfamiliariza e reestrutura a experiência do próprio presente. Por isso, não são simplesmente representações que fornecem imagens do futuro, mas estratégias que visam intensificar a relação individual com o presente. Na opinião do autor, trata-se de uma mobilização do futuro a fim de determinar uma volta a um presente agora histórico. Por outro lado, Jameson ( $A$ Virada cultural) aponta como nostálgicas as operações que mobilizam uma visão do passado de forma alegórica, reduzindo-as à recombinação de vários estereótipos do passado.

Delimitando-se a compreensão do retrofuturismo como uma operação nostálgica, restringe-se a proposta à imaginações do passado sobre o futuro, ou seja, como artefatos históricos de velhas ideologias sobre o progresso humano, cuja remobilização, no presente, podem ser usadas como meios de refletir sobre as falhas daqueles sonhos em se tornar realidade. Ou então, como a certeza de que os piores medos para com o futuro próximo se concretizaram. Entretanto, a proposta da ficção científica retrofuturista vai além dessa possibilidade. Jenkins, em seu texto “"The Tomorrow that Never Was': Retrofuturism in the Comics of Dean Motter Part One", explica que ela serve para trabalhar no intervalo entre um futuro antecipado e a realidade vivida, oportunizando experiências em temporalidades híbridas.

O retrofuturismo, fruto da ficção científica contemporânea, propõe analisar o papel que os fatores sociais e culturais desempenham na forma como o ser humano vive e interage com a tecnologia (Jenkins, "“The Tomorrow that Never Was': Retrofuturism in the Comics of Dean Motter Part One"). Também reitera o papel da subjetividade na forma de visualizar o futuro em diferentes épocas, mas nem sempre sob a ótica do progresso científico e tecnológico. Dessa forma, o retrofuturismo pode ser entendido como o processo pelo qual ideias que uma vez eram emergentes e pareciam ser futuristas em suas aplicações podem ser transformadas em elementos residuais de uma cultura que passa por mudanças rápidas e dramáticas.

É pertinente a diferença apontada por Jenkins (“"The Tomorrow that Never Was': Retrofuturism in the Comics of Dean Motter Part Two") nos rumos da ficção científica. 
A antiga proposta do gênero partia de um futuro imaginário e de um passado real. Atualmente, as histórias são elaboradas principalmente a partir de um passado imaginário baseado no futuro que se concretizou, ou que foi prometido e não se cumpriu. É o mundo do amanhã imaginado que nunca partiu, diz o autor:

[...] eles [os autores de ficção científica] usam estas imagens para apresentar uma leve crítica às ideologias que moldaram estas primeiras imagens de futuro. Ao longo de tudo isso, nós sentimos uma certa melancolia no nosso reconhecimento de que o mundo imaginado do amanhã nunca veio, ou mais precisamente, nestas histórias, ele veio e nunca partiu. De qualquer maneira, o resultado é um conjunto de sonhos despedaçados e promessas quebradas. ' (Jenkins, “"The Tomorrow that Never Was': Retrofuturism in the Comics of Dean Motter Part Three”, tradução nossa)

O steampunk segue essa linha, pois as histórias giram em torno das conquistas científicas e tecnológicas do século XX: das apenas imaginadas, das concretizadas até aquelas que decepcionaram. Tais invenções são inseridas preferencialmente no contexto do século XIX, avançando o futuro em direção ao passado, ou promovendo uma interrupção no avanço tecnológico tal qual o conhecemos e, em seu lugar, imaginando o mundo sob o desenvolvimento do vapor. Em outras palavras, o steampunk trabalha na linha entre o que foi, o que poderia ter sido e as extrapolações inventivas dos próprios participantes (desde escritores a adeptos da cultura urbana).

Portanto, o passado e o futuro descritos por essa cultura retrofuturista não são o mais importante aspecto de suas propostas, mas as estratégias que ele sugere a partir das ressignificações de temporalidades. O steampunk revisualiza, ressignifica esse passado, inserindo elementos de temporalidades diversas, criando um tempo diferenciado, que não é simplesmente mimético, idealista ou utópico. As possibilidades das temporalidades steampunk são variadas: um futuro que não aconteceu, quando utilizam o vapor como a tecnologia que teria dado certo; um passado que ocorreu transformado pelas conquistas do presente; um futuro desse passado que aponta, simultaneamente, as conquistas e as piores consequências de um presente biotecnológico; um futuro pessimista, caótico, desenvolvido tecnologicamente, que pode ser inserido em qualquer temporalidade imaginada (ou realmente vivida).

\footnotetext{
"[...] they are using these images to pose a mild critique of the ideologies that shaped these earlier images of the future. Throughout all of this, we feel a certain melancholy in our recognition that the imagined world of tomorrow never came or more accurately, in these stories, it came and never left. Either way, the result is a set of shattered dreams and broken promises."
} 
Os marcadores temporais do retrofuturismo em culturas urbanas como o steampunk, com seus questionamentos à temporalidade e à racionalidade, também apontam mudanças nas percepções a respeito do futuro e daquilo que se pode chamar de experiência de cidade, ou seja, na forma de relacionamento das práticas urbanas e de conceber os espaços sociais.

A complexidade da experiência urbana é tecida por Sennett (368) para refletir sobre as "muralhas erguidas em torno da capacidade de percepção", quando se relacionam corpos e espaços por onde circulam. Ele mostra que as relações entre carne e pedra também estão incutidas no tempo e no espaço. E salienta um aspecto importante dessa relação: as experiências corporais no espaço da cidade são interativas e não simplesmente uma atitude passiva por parte de nenhum dos lados.

A cidade tem sido um lócus de poder, cujos espaços tornaram-se coerentes e completos à imagem do próprio homem. Mas também foi nelas que essas imagens se estilhaçaram, no contexto de agrupamentos de pessoas diferentes - fator de intensificação da complexidade social - e que se apresentam umas às outras como estranhas. Todos esses aspectos da experiência urbana - diferença, complexidade, estranheza - sustentam a resistência à dominação. (Sennet 25)

As experiências corporais em seu uso do espaço urbano agenciam comportamentos, interações e formas de visualizar a cidade. A seguir, apresenta-se uma compilação das principais características que o espaço urbano assume nos contos steampunk da primeira coletânea brasileira do gênero - Steampunk: histórias de um passado extraordinário (Celli). A obra reúne histórias que abordam as inquietações de um espaço social marcado pela tecnologia, nas quais é facilmente perceptível a influência cyberpunk em relação às críticas quanto ao desenvolvimento social e à degradação do indivíduo.

O contexto para as narrativas steampunk é o espaço urbano moderno, em sua concepção. A tradição vem da própria literatura de ficção científica e, especialmente, do subgênero cyberpunk, que traça um panorama sombrio, poluído e desorganizado do espaço urbano, com suas gigantes e claustrofóbicas obras de arquitetura futurista. Este mundo da ficção é criado a partir dos próprios sobressaltos que a modernidade propiciou ao ambiente hiperestimulado e especificamente urbano, sujeitando o indivíduo moderno a um bombardeio de experiências caóticas, fragmentadas e desorientadoras (Singer).

ParaAmaral, a cidade sombria e envolta no submundo, derivada da estética technoir, é uma figura marcante do cyberpunk. É nesse ambiente carregado e esquizofrênico que a subjetividade humana define-se. No steampunk, as críticas e os questionamentos seguem rumos diferenciados do cyberpunk, ainda que insinuem o fracasso da razão nas narrativas que optam pela distopia ou pelo pós-apocalíptico. Nessas histórias, as 
temáticas são variadas: caos urbano, violência, destruição, tecnologia usada de maneira errônea, guerras.

O ambiente urbano é contextualizado como o lugar por excelência para a exibição das conquistas tecnológicas e científicas. Em alguns casos, as histórias se passam nas selvas brasileiras ainda em início de desbravamento, nos ares ou nos mares, a bordo de complexos meios de transporte com tecnologia futurista na Era do Vapor Steampunk. A forma de relatar as cidades reflete maneiras de pensar o espaço urbano, com suas dinâmicas, suas problemáticas, suas potencialidades. As ruas dividem espaço com carruagens a vapor, cavalos e pedestres. Os céus são invadidos por balões, dirigíveis e aviões.

Veículos grandes e pequenos soltando fumaça pelas ruas; navios de passageiros e de carga cruzando o Tâmisa; pequenos balões, presos a edifícios ou soltos, voando ao sabor do vento. Nada que ele já não tivesse visto em Santos [São Paulo, Brasil], nos arredores do Instituto Luso-brasileiro Padre Bartolomeu Gusmão de Aeronáutica, onde trabalhava como professor-assistente e engenheiro. Porém, ali, o que impressionava era a intensidade, a quantidade de máquinas. (Villa 11)

Algumas das principais cidades de fins do século XIX e alvorecer do novo século são o palco das aventuras steampunk: Londres, Liverpool, Rio de Janeiro. Elas contextualizam o ambiente de progresso da Revolução Industrial.

[...] Liverpool era uma cidade grande e urbanizada, com suas ruas e vielas se estendendo até onde os olhos alcançam. [...] Os armazéns que ocupavam boa parte das docas não passavam de grandes galpões erguidos com tijolos agora escurecidos e cobertos por limo. Vagando por entre eles estava toda estirpe de vagabundos, prostitutas e estivadores, que gastavam seus parcos ganhos com jogos de azar e sexo barato. $\mathrm{O}$ ambiente era opressivo e eu podia notar como aqueles homens e mulheres, esquecidos por Deus e pela sociedade, lançavam olhares de ódio ao notar que eu não era da cidade. (Villa 115)

A fumaça, elemento sintomático da Revolução Industrial, também é a metáfora de um processo irreversível de progresso que tem seu preço para o homem e para o meio ambiente.

Uma das consequências da industrialização é a fumaça que faz parte do cotidiano das pessoas que adotaram a maior cidade das Américas como lar ou local de trabalho. Uma neblina suja capaz de impregnar tato, paladar e olfato de todos [...] sai do conjunto formado por centenas de obeliscos de pedra espalhados pela Capital. São as chaminés das indústrias, verdadeiros monstros que, com seus fornos, alimentados pelo carvão de Santa Catarina, produzem trilhos, locomotivas, cascos de navios e novos fornos. O futuro movido a vapor e materializado em metal. (Martins 146) 
O conto abaixo retrata um cenário steampunk pós-apocalíptico, a cidade-fábrica Catalônia. Lugar perigoso, sujo, violento, subversivo, cheio de facções políticas (sindicalistas, republicanos, anarquistas), mas ao mesmo tempo local de refúgio para os inumanos que conseguem escapar da tirania de humanos e grupos dominantes.

Havia gente, no entanto. Uma babel desembarcando com sotaques genoveses e madrilenhos, e outros balcânicos e otomanos, confusos demais para se distinguir. E expatriados do império brasileiro também, e mais mauritzes. Homens vestindo marrom e algodão barato, alguns com parafusos frouxos ou enferrujados, vazando vapor pelas juntas, além de mulheres de olhar severo, vestidos manchados de carvão e calos, carregando pouca bagagem, mas todos rindo com o prazer de pisar em terra firme. (Barcia 125)

Geralmente, as histórias têm um pano de fundo bélico ou de disputas por domínio de tecnologia, de armamentos, de descobertas científicas. As narrativas exploram as tentativas de controle de comportamento social, por meio da utilização das conquistas científico-tecnológicas pelos grupos detentores de poder. Dos nove contos que compõem a coletânea, sete envolvem direta ou indiretamente guerra e tecnologia. Os outros dois abordam, respectivamente, uma descoberta científica no campo da medicina e uma invenção com alto poder destruidor.

Ainda que as narrativas envolvam disputas, brigas e poder, a violência não aparece fora de controle como na distopia cyberpunk. Na maior parte das situações, a violência está na iminência de acontecer, caso o personagem principal não intervenha de alguma forma, ou seja, ele não é apenas uma vítima das circunstâncias, mas um agente ativo que pode alterar o rumo da situação.

Elemento essencial são os armamentos, dos mais diversos gêneros, para os mais diferentes objetivos, e que potencializam o contexto de violência das histórias, conforme exemplificado nos fragmentos de contos que se seguem:

Este é um fuzil de tiro fixo Guarany, fabricado no Paraguai, arma exclusiva do Império. Uma obra-prima da mecânica: o coice de um tiro engatilha o seguinte. Basta apertar o gatilho uma vez para disparar até acabarem os cartuchos. (Martins 144)

A Mauser C-96 ia num coldre de madeira, incômodo de se usar na cintura, mas que se transformava em coronha atarrachável [sic] à empunhadura de nogueira. A pistola, de cano de 14 centímetros e carregador de dez munições, virava uma carabina com alcance efetivo de 200 metros. (Causo 83)

Hoje comando pessoalmente a unidade mais antiga, mas ainda a mais temível de toda a frota francesa de submergíveis que faz tremerem as tripulações dos navios ingleses no Atlântico e no Canal da Mancha. O poder explosivo de meus torpedos 
é insuperável. Minhas metralhadoras de repetição da proa transformam carne em poeira sangrenta. Meus pioneiros mísseis terra-ar permanecem como exclusividade da marinha francesa, e podem atingir uma fortaleza voadora sem que o submergível tenha ainda que estar visível na superfície do oceano. Assim eu me tornei o rei dos mares, enquanto o maldito estadunidense que se encontra em algum lugar na escuridão que me cerca dominou os ares com seus dirigíveis de batalha, em favor do Império Britânico. Permanece o frágil equilíbrio das forças antagônicas que comandam o planeta. (Medeiros 166-167)

As menções à tecnologia são constantes em todos os contos, tematizando uma sociedade que tenta se adequar aos avanços e aos preços do progresso tecnológico. Em alguns momentos, apontam-se os aspectos positivos, insinuando os benefícios da tecnologia; em outros, questionam-se os aspectos negativos da relação com o homem.

[...] mas vivemos tempos modernos, uma era onde nós homens racionais estamos superando gradativamente os obstáculos da natureza. Desde que dominamos a força do vapor, não existem mais limites que não possam ser rompidos. Nossos brilhantes cientistas romperam a barreira que separa o homem do fundo do oceano, tornando tarefas - antes impossíveis - em atividades corriqueiras. (Villa 112)

O refinamento da civilização trouxe os avanços tecnológicos; na maioria das vezes, admito e declaro aqui a mea culpa, criados para agir a serviço da morte e do domínio do semelhante. Trouxe também a chamada "diplomacia" que, para mim, não passa de uma tentativa hipócrita de minimizar as perdas e os curiosos "códigos de ética". (Medeiros 164)

Um dos contos aborda outra temática que aproxima a narrativa steampunk do subgênero que lhe deu origem, o cyberpunk. No conto "Uma Breve História da Maquinidade", os autômatos entram em guerra com os humanos pelo direito de serem reconhecidos como uma "espécie" - assim como a humana - com igualdade de direitos. A história simultaneamente alerta para a maquinização do âmbito social e para a subjetivação das máquinas que, embora concebidas como seres pensantes, "não têm moral nenhuma".

Sendo, é claro, o primeiro grupo tecnológico na História, os Cérebros Mecânicos lutaram por seus direitos. Não demorou muito para que eles, depois de praticamente obrigarem seus senhores humanos a declarar uma trégua e ganhar o direito de seres [sic] declarados seres sencientes, se autodenominarem não uma nova humanidade, como queriam alguns filósofos e pensadores, mas Maquinidade. (Fernandes 33)

Outro conto também trabalha o steampunk a partir da subjetivação de autômatos. Entretanto, em "Uma vida possível atrás das barricadas", os inumanos são vítimas das 
ações cruéis dos homens. Fritz, o personagem principal, lembra os robôs sensíveis das histórias de Isaac Asimov. Sonhador, foge com a esposa para escapar da escravidão humana e recomeçar em Catalônia, o cenário pós-apocalíptico citado anteriormente.

Era, mesmo assim, um autômato que sonhava com o campo, com o cadeado quebrado, com dias de sol e com os cumprimentos dos transeuntes. Sonhava ser herói, imaginava lendas onde era livre depois de batalhas contra um inimigo tirânico, opressor. Mas nunca pegou num fuzil, nem para caçar no bosque, perto do monte dos Guararapes, com o Sr. Goradeski. Sua função era somente contabilizar os bens do seu senhor e tutorar os herdeiros do clã. (Barcia 125)

É interessante observar que os personagens principais dos contos citados enquadramse no padrão do herói, dispostos a se sacrificar para o bem coletivo. Essa característica destoa das construções identitárias de vários participantes do grupo steampunk de Curitiba, pois muitos destes preferem que seus personagens sejam os anti-heróis ou vilões, com o objetivo de fugir ao convencional das narrativas ficcionais.

Dificilmente as histórias giram em torno de um contexto de vida privada dos personagens. Uma ou outra característica desse ambiente pode incrementar os contos, mas é a cidade que se fixa como elemento definidor de subjetividade e interação dos personagens. Os indivíduos das narrativas steampunk são frequentadores dos círculos da alta sociedade, professores universitários, cientistas, aventureiros, marinheiros. Trata-se de um espaço eminentemente adulto. Vários contos misturam figuras históricas, indígenas, literárias ou místicas.

Constata-se que a presença das mulheres é recorrente. Ao contrário dos romances do século XIX, em que as figuras femininas que despertavam admiração eram tímidas, frágeis e submissas, no universo steampunk, como heroínas ou vilãs, elas têm personalidade, são inteligentes, aventureiras e destemidas:

Mesmo se não fosse o sangue índio a dar tal impressão, o olhar dela não deixaria dúvidas de que se trata de alguém disposto a matar ou morrer. (Martins 143)

A doutora, contou o marido, era do povo maia. Sua família participara de uma insurreição contra o Império Mexica há cinquenta anos. Derrotados, haviam fugido e se asilado em nossa colônia no Panamá, onde ela nasceu e de onde veio ao Brasil estudar, ainda menina. Dois terços desta e de outras descobertas [medicinais] que lhes mostrarei lhe pertencem, disse-nos o marido, com orgulho. (Costa 41)

Sem usar do clichê final feliz, os fins dos contos sempre apontam um lampejo de esperança, sinalizando que as críticas levantadas pelo retrofuturismo steampunk não significam simplesmente um pessimismo fatalista e irreversível, ou a aversão a 
tecnologia. As divagações finais do almirante Nemo, personagem de um dos contos, bem sintetizam essa ideia:

Após todo esse tempo, meu caro, aquilo que ainda nos torna humanos está preso por um fio, dependurado sobre o abismo da selvageria. Homens de honra precisam viver sob um código de ética que nos faça lembrar que, apesar de tudo, ainda somos humanos. (Medeiros 179)

Portanto, a distopia não é o principal condutor das histórias steampunk. A atmosfera perigosa e poluída das narrativas é contrabalanceada pelas pinceladas românticas que buscam inspiração na Era Vitoriana. A seguir, outra faceta do steampunk será mostrada, referente às apropriações que os participantes fazem dessa cultura urbana retrofuturista e suas respectivas performances no espaço urbano.

\section{DA Literatura Ao ESPAÇO URBANO}

Sodré afirma que a sociedade contemporânea rege-se pelo que chama de midiatização, a partir da articulação entre as pautas individuais de conduta e as tecnomediações possibilitadas pelas tecnologias da comunicação. O autor reforça o argumento de que a mídia é estruturadora de percepções e cognições. "A midiatização pode ser pensada como um novo bios, uma espécie de quarta esfera existencial, com uma qualificação cultural própria (uma 'tecnocultura'), historicamente justificada pelo imperativo de redefinição do espaço público burguês" (Sodré 22). Por isso, a tecnocultura constituída por esse novo bios implicaria um novo tipo de relacionamento do indivíduo para com as referências concretas e a verdade.

Contudo, a posição de Sodré é criticada por Leal, Mendonça e Guimarães, pois no processo de midiatização caracterizado por aquele autor não haveria lugar para a experiência estética, que não passaria de sensorialidade exacerbada. "Nessa caracterização, ecoam fortemente as teses de Debord: o caráter enganador das aparências sensíveis, a anulação do sujeito (que quanto mais contempla menos é), separado da verdade, desalojado do mundo pelo espetáculo, que está em toda parte" ("Experiência Estética e comunicação" 13).

A respeito do assunto, Braga (75) tem uma posição interessante. Para ele, a mediatização não diz respeito apenas ao aparato tecnológico-econômico, mas também aos aspectos centrais de interação social. Ele argumenta que a mediatização envolve interações sociais muito mais diversas do que aquelas apenas restritas à confrontação direta com as mídias tecnológicas ou com seus produtos. Dessa forma, ela não marca apenas formas de organizar e transmitir mensagens, mas envolve, principalmente, os modos pelas quais se constitui o tecido social. "São padrões para 'ver as coisas', para 
'articular pessoas' e mais ainda, relacionar subuniversos na sociedade e-por isso mesmo - modos de fazer as coisas através das interações que propiciam" (Braga, "Mediatização como Proceso" 148). Para o autor, a mediatização é formada por processos transmissivos e interacionais permeados por lacunas, insuficiências, incompletudes, bem como por processos de resistência e subtração à lógica sistêmica.

A sociedade vai fazendo, com as instruções que tem à mão - adequadas ou não - e com o próprio fazer tentativo vão sendo geradas as instruções de rearranjo. A incompletude se evidencia aqui pela indefinição dos subuniversos ou setores sociais em que a realidade possa ser apreendida e constituída de modo suficientemente "estável" para viabilizar comutações eficientes. (Braga, "Mediatização como Proceso" 161)

Essas ideias do autor acima mencionado podem ser entendidas como agenciamentos que ocorrem no contexto social. As concepções de Deleuze e Guattari (Mil Platôs) sobre os agenciamentos maquínicos e de enunicação são pertinentes para a compreensão desse processo. Os agenciamentos maquínicos dizem respeito à mistura e às relações entre os corpos em sociedade. Os agenciamentos coletivos de enunciação referem-se ao regime de signos compartilhados. Tais agenciamentos estão um no outro, intervindo um no outro. "Não existe enunciado individual. Nunca há. Todo enunciado é o produto de um agenciamento maquínico, quer dizer, de agentes coletivos de enunciação (por 'agentes coletivos' não se deve entender povos ou sociedades, mas multiplicidades)" (Deleuze e Guattari, Mil Platôs v. 1, 51).

Os agenciamentos de enunciação são produtores de processos de subjetivação esta entendida como modos de produção de si - os quais não são centrados em agentes individuais ou grupais (Guattari e Rolnik), mas descentrados.

Implicam o funcionamento de máquinas de expressão que podem ser tanto de natureza extra-pessoal, extra-individual (sistemas maquínicos, econômicos, sociais, tecnológicos, icônicos, ecológicos, etológicos, de mídia, enfim sistemas que não são mais imediatamente antropológicos), quanto de natureza infra-humana, infrapsíquica, infrapessoal (sistemas de percepção, de sensibilidade, de afeto, de representação, de imagens, de valor, modos de memorização e produção de idéia, sistemas de inibição e de automatismos, sistemas corporais, orgânicos, biológicos, fisiológicos, etc.). (Guattari e Rolnik, Micropolítica 31)

Dessas considerações, é importante estabelecer que uma parcela significativa do cotidiano, das posturas e dos valores de cada um organiza-se imersa nesse processo de mediatização, que podem tornar-se vetores de experiências e percepções, e que os indivíduos não são agentes passivos, sem nenhum poder de decisão sobre aquilo que apreendem. Os participantes do steampunk, a partir de suas experiências visuais e 
socialidades delas decorrentes, realizam agenciamentos da cultura midiática, promovendo uma transgressão negociada entre passado, presente e futuro.

Nesta etapa do texto, serão apresentadas algumas das performances dos steamers de Curitiba, capital do Paraná, na região Sul do Brasil, que compõem a Loja Paraná do Conselho Steampunk. ${ }^{2}$ O grupo é heterogêneo em sua formação, reiterando as características de fluidez, efemeridade e diversidade das neotribos (Maffesoli). Os participantes reúnem-se frequentemente para promover atividades relacionadas ao steampunk, bem como para participar de eventos de outras culturas urbanas.

No Brasil, os steamers agrupam-se, em cada Estado e denominam-se "lojas", embora não objetivem comercializar produtos. O termo é empregado no sentido sugerido pela maçonaria, de ajuda mútua entre os envolvidos. A Loja Paraná do Conselho Steampunk é uma das mais ativas do Brasil, oferecendo regularmente oficinas de customização que reúne número significativo de interessados em aprender a confeccionar roupas, objetos e acessórios para a prática do steamplay (adaptação do termo cosplay para o universo steampunk). Outro tradicional momento de socialidade do grupo é o evento anual conhecido como Café a Vapor Steampunk, programação cultural que propicia aos participantes apresentarem as mais diversas performances de dança, música, literatura, customização, artesanato.

Jenkins (Piratas de textos) mostra que os fãs abraçam seus textos preferidos e integram as representações dos meios de comunicação em suas próprias experiências pessoais. Aquilo que para alguns é simples aceitação passiva de produtos massivos, para o autor é a perversão estética aos limites tradicionais impostos pelas hierarquias culturais dominantes que delineiam as culturas desejáveis e as não desejáveis. Ele adapta o conceito de leitor de Michel de Certeau para propor que os fãs tornam-se produtores ativos de significados, que leem e se apropriam de textos midiáticos, reelaborando-os de acordo com seus interesses e transformando a experiência em uma cultura participativa rica e complexa. “A noção de De Certeau de 'caça furtiva de textos' centra sua atenção na capacidade de ação dos leitores. O leitor não é arrastado para um mundo pré-construído da ficção, mas a um mundo que foi criado a partir de materiais textuais"(Jenkins, Piratas de textos 83; tradução nossa). ${ }^{3}$ Dessa forma, eles constroem uma identidade cultural e social mediante apropriação e modificação dos significados dos produtos culturais que

2 Os apontamentos apresentados aqui fazem parte da pesquisa de doutorado da autora, que consistiu no acompanhamento das atividades da Loja Paraná do Conselho Steampunk, utilizando-se de observação participante e estudo de caso. Os participantes mais regulares e ativos do grupo foram entrevistados. Alguns fragmentos dessas entrevistas são utilizados aqui para auxiliar na compreensão dos objetivos do presente artigo.

3 'La noción de De Certeau de 'caza furtiva de textos' centra su atención en la capacidad de acción de los lectores. El lector no es arrastrado al mundo preconstruido de la ficción, sino un mundo que ha creado a partir de los materiales textuales". 
circulam pelos meios de comunicação, como forma de expressar suas próprias visões de mundo.

[...] os fãs afirmam de forma ativa seu domínio sobre os textos produzidos em massa que proporcionam a matéria-prima para as suas próprias criações culturais e a base para suas interações sociais. No processo, os fãs deixam de ser um simples público dos textos populares para converter-se em participantes ativos na construção e circulação de significados textuais. ${ }^{4}$ (Jenkins, Piratas de textos 38; tradução nossa)

Os steamers não constituem um grupo de fãs no sentido literal proposto por este autor, mas caracterizam-se como uma comunidade mais ampla de simpatizantes do steampunk que também se dão ao direito de fazer suas próprias interpretações dos textos da cultura da mídia, reelaborando-os de acordo com suas interações sociais e experiências culturais. Eles investem na apropriação cultural de diferentes textos, tais como obras de ficção científica, filmes, quadrinhos e jogos de RPG, conferindo-lhes novos significados, expandindo as histórias, aprofundando características de personagens e reformulando contextos de acordo com suas capacidades imaginativas. As criações podem, inclusive, sugerir misturas impossíveis nos textos que lhes deram origem, como a inserção de personagens ficcionais ou históricos de diferentes períodos e histórias na mesma narrativa.

No caso da Loja Paraná do Conselho Steampunk, os steamers partem dos produtos da cultura da mídia que mais lhes interessam e se tornam produtores de novos textos de uma cultura participativa, que inclui: narrativas ficcionais, fotonovelas, ilustrações, ensaios fotográficos, customização de objetos, artesanato, performances de dança e musicais, produção de moda e acessórios, eventos. Portanto, a leitura ou apropriação feita pelos adeptos do steampunk é um processo social e público que toma forma a partir de dois movimentos: as produções individuais potencializadas pelo DIY (Do It Yourself, do movimento punk) de um lado; e de outro, pela concepção contemporânea DIT (Do It Together) - algo como façamos juntos - propiciada pela construção coletiva nos espaços de socialidade da Loja Paraná do Conselho Steampunk.

Neste artigo, como exemplo dessa argumentação são utilizadas as fotonovelas produzidas pelo grupo do Sul do Brasil. A primeira fotonovela steampunk brasileira como os steamers curitibanos orgulham-se de indicar - é resultado da mistura do DIY com o DIT. A fotonovela Carnivale Steampunk (Loja Paraná do Conselho Steampunk) é a produção coletiva que reúne as performances individuais dos integrantes da Loja

\footnotetext{
4 “...] los fans afirman de forma activa su dominio sobre los textos producidos en masa que proporcionan la materia prima para sus propias creaciones culturales y la base para sus interacciones sociales. En el proceso, los fans dejan de ser un simple público de los textos populares para convertirse en participantes activos en la construcción y circulación de significados textuales".
} 
Paraná do Conselho Steampunk. Por meio das experiências estéticas e dos ensaios fotográficos do grupo, o produto mistura narrativa literária, produção fotográfica e sonora com performances dos seus integrantes. Veiculada no Youtube, foi criada, produzida e contracenada pelos steamers, em vários cenários de Curitiba. A customização das indumentárias e dos acessórios, bem como maquiagem e demais objetos de cena também foram feitos pelos participantes.

A narrativa envolve as histórias dos personagens integrantes da loja, ou seja, foi criada a partir da junção das criações identitárias individuais dos steamers (para a prática do steamplay). A trama baseia-se na mistura clássica das histórias de ficção científica: viagens temporais, tecnologia e armas, permeada por uma intriga amorosa. A produção fez sucesso e, a pedido de steamers de outros países com os quais os brasileiros interagem, foi traduzida para o inglês - Carnivale Steampunk - English version (Loja Paraná do Conselho Steampunk).

As criações identitárias dos personagens, bem como a trama e a contextualização dessa produção são frutos primordiais do interesse dos participantes pela ficção científica, bem como de outros produtos da cultura da mídia. As respostas abaixo de alguns dos participantes da Loja Paraná do Conselho Steampunk comprovam o interesse pelas narrativas de Fiçãa científica que, posteriormente, inspiraram as performances dos steamers em suas produções individuais e coletivas:

Procuro inspiração nas obras do Júlio Verne, do H. G. Wells, do Edgar Allan Poe [...] Trabalho com pessoas reais, personagens reais, por exemplo, a rainha Vitória, Bismarch, Napoleão III. [...] A Revolução Meijin, do Japão, também fornece muitos elementos, pois eles [os japoneses] são mais próximos da história do steampunk, porque eles tentam mesclar os elementos da sociedade cultural deles, clássica, samurai, com os elementos da sociedade européia. (A.F.W.L., 23 anos, masculino, historiador, consultor de teatro)

Tem um leque gigante [de pesquisa], tem muito no mundo dos games, assim como de livros, as histórias de Júlio Verne (as ideias de construção, de pesquisa que ele tem), televisão, filme, um pouco de tudo, não tem uma coisa fixa, vejo uma coisa que eu acho legal e tento fazer parecido, então eu adapto como se fosse steampunk. (E. E. F., 26 anos, masculino, mediador cultural, graduado em Desenho)

A primeira vez que eu ouvi falar em steampunk foi num grupo em que eu participava de ficção científica. Sempre estive envolvido com isso. A gente fez uma confraria de escritores de ficção científica, aqui em Curitiba, de 2000 até 2005. ("Entrevista")

É interessante observar que, para muitos steamers, participar dessa cultura urbana retrofuturista representa a oportunidade de criar suas próprias narrativas. Em outras

Entrevista concedida pessoalmente a autora em 11 fev. 2012, em Curitiba, Paraná. 
palavras, não é uma simples ação mimética a partir do consumo de literatura de ficção científica ou de outros produtos da cultura da mídia. É a possibilidade de extrapolar as histórias que admiram ou de desenvolver seu potencial imaginativo em novas criações.

Eu acho que o maior atrativo é que você pode criar o que você quiser no steampunk, você tem muito espaço [...] Você pode criar um personagem, você pode criar a sua história, do jeito que quiser, como ela quiser. E a parte da literatura é fundamental. Leio muitos livros, como Júlio Verne. (D.D., 29 anos, masculino, técnico de refrigeração e ar-condicionado)

Realmente, eu me encontrei no steampunk. Eu gosto dessa coisa de criar e recriar as coisas. Eu trabalho com arquitetura, então, por conta disso, acho que me interessou mais ainda. (D.C.; 25 anos; feminino; arquiteta)

Sempre participei dos eventos em Curitiba, dos trekkers, ou do Star Wars, ou quando acontece eventos de anime também. Então, o steampunk abriu esse leque, a possibilidade de eu desenvolver algo em cima, criar um personagem e transformar ele em outra coisa. (E. E. F., 26 anos, masculino, mediador cultural, graduado em Desenho)

Para mim, primeiro, steampunk é literatura. [...] Steampunk é você poder ter essa visão elegante do passado, com a tecnologia de hoje. E também usando as ferramentas que a gente teria na época. É poder criar as coisas como se a gente tivesse naquela época, mas com conhecimento de agora. É como se tivesse um certo poder, porque você está lá, mas sabe como fazer as coisas de hoje, é como se você fosse um viajante do tempo. (R.C., 24 anos; masculino; consultor de implantação)

Os steamers curitibanos interagem com outros grupos steampunk e outras culturas urbanas no Brasil. Além da participação em eventos e da troca de informações pelas redes sociais, no começo deste ano lançaram uma fotonovela em parceria com o grupo de steamers de Campinas, de São Paulo. O Sequestro na Ferrovia (Loja Paraná do Conselho Steampunk; Full Steam - the Steampunk Group Campinas) também centrase na luta entre vilões e mocinhos, tendo como principal cenário um trem a vapor que faz parte da programação turística de Campinas.

Apesar das limitações compreensíveis de uma produção amadora, as fotonovelas elaboradas podem ser caracterizadas como produtos visuais resultantes da socialidade de uma cultura urbana que se reúne em torno do interesse comum pela ficção científica e pelo retrofuturismo steampunk. Além disso, percebe-se, o interesse comum entre a maior parte dos steamers (sejam eventuais ou ativos e regulares) pela ficção científica, seja da literatura ou do cinema, bem como pelos produtos da mídia que integram o cotidiano desses participantes, como games, jogos de RPG, animes e HQ's. Ainda que o steampunk tenha iniciado em terras estrangeiras e tenha como pano de fundo o contexto vitoriano 
do século XIX, não significa que as motivações dos participantes sejam nostálgicas ou miméticas. É possível afirmar que essa cultura urbana retrofuturista foi apropriada e reelaborada de forma localizada pelo steampunk paranaense e hoje serve de referência para outras lojas do país. Esses steamers imprimiram características próprias ao que compreendem sero steampunk, agregando traços distintos de outros grupos mundo afora.

\section{Considerações Finais}

Que as narrativas da ficção científica disseminadas na literatura, no cinema e em demais produtos da mídia têm o seu público cativo, não é novidade para ninguém. Mesmo com todas as mudanças tecnológicas e com o receio de muitos de que os livros, em sua forma tradicional, estão se extinguindo, as apropriações do steampunk pelos participantes espalhados Brasil (e mundo) afora comprovam que inusitadas alternativas surgem no seio do público cativo da ficção científica em seus variados subgêneros. Mais do que a leitura das obras que lhes interessam, os steamers agenciam suas próprias narrativas por meio de performances. É a vontade de materializar sua imaginação, de corporificar suas ficções.

Ao longo da pesquisa, foi possível constatar que vários deles participam dos dois lados do processo-como leitores e como escritores-produzindo um circuito micromídia (Thornton) de contos literários, de histórias em quadrinhos, de ilustrações, de artesanato e de várias outras manifestações artísticas. Embora a maioria dessas produções não chegue ao mainstream - o que nem interessa a muitos deles - a possibilidade de circular e de serem conhecidas pelo grupo satisfaz os desejos imediatos de consumo simbólico.

Oretrofuturismo praticado por diversas culturas urbanas como o steampunk tem um vínculo forte e fundamental com o gênero que lhe deu origem, a ficção científica. Ele propicia espaços de socialidade entre os seus participantes, bem como potencializa formas diversificadas de crítica social, principalmente no que se refere à cultura tecnológica que permeia o cotidiano e agencia subjetividades.

Apertinente pergunta “e se tivesse sido diferente?" salienta que o passado imaginário do steampunk fala mais a respeito das profundas alterações perceptivas da experiência espaço-temporal contemporânea do que de uma simples nostalgia pelo que passou. Tais alterações sinalizam um hibridismo de temporalidades e espaços que se fazem perceber na forma de sentir e vivenciar o espaço urbano, por exemplo.

Nas narrativas literárias steampunk, o contexto do mundo a vapor imaginado é permeado pelas disputas que envolvem ciência, tecnologia e poder. Mesmo assim, a distopia é equilibrada com o lado romântico das ladies e dos gentlemen do século XIX que vivem uma temporalidade híbrida entre passado, presente e futuro.

No espaço urbano, os steamers concretizam suas próprias narrativas ficcionais, por meio das mais diversas performances. Elas revelam maneiras diferenciadas de 
práticas urbanas e de conceber os espaços sociais. Também indicam diferentes formas de agenciamento da cultura da mídia que ultrapassam o consumo passivo, individual e irreflexivo. Os produtos e as perfomances deles ganham visibilidade e concretizam-se na cena steampunk, um espaço lúdico que mistura entretenimento, fruição e crítica social.

\section{REFERÊNCIAS}

Amaral, Adriana. Visões Perigosas: uma arque-genealogia do cyberpunk. Porto Alegre: Sulina, 2006.

Barcia, Jacques. "Uma vida possível atrás das barricadas”. Steampunk: Histórias de um passado extraordinário. Gianpaolo Celli. São Paulo: Tarja Editorial, 2009. 123-140.

Braga, José Luiz. "Experiência estética \& mediatização". Entre o sensível $e o$ comunicacional. Bruno Leal; Carlos Mendonça; César Guimarães, org. Belo Horizonte: Autêntica, 2010. 73-87.

"Mediatização como processo interacional de referência". Imagem, Visibilidade e cultura midiática. Livro da XV Compós. Ana Sílvia Lopes Davi Médola; Denize Correa Araujo; Fernanda Bruno, org. Porto Alegre: Sulina, 2007.

Causo, Roberto de Sousa. "O plano de Robida: un voyage extraordinaire". Steampunk: Histórias de um passado extraordinário. Gianpaolo Celli. São Paulo: Tarja Editorial, 2009. 75-108.

Celli, Gianpaolo, org. Steampunk: Histórias de um passado extraordinário. São Paulo: Tarja Editorial, 2009.

Costa, Antonio Luiz M. C. “A flor do estrume”. Steampunk: Histórias de um passado extraordinário. Gianpaolo Celli, org. São Paulo: Tarja Editorial, 2009. 37-48.

Deleuze, Gilles e Félix Guattari. Mil Platôs. Vol. 1. São Paulo: Editora 34, 1995. e Félix Guattari. Mil Platôs. Vol. 2. São Paulo: Editora 34, 1995.

Fernandes, Fábio. “Uma breve história da maquinidade". Steampunk: Histórias de um passado extraordinário. Gianpaolo Celli, org. São Paulo: Tarja Editorial, 2009. 29-36.

Guattari, Félix e Suely Rolnik, Suely. Micropolitica: cartografias do desejo. Rio de Janeiro: Vozes, 2005.

Jameson, Fredric. A Virada cultural. Reflexões sobre o pós-moderno. Rio de Janeiro: Civilização Brasileira, 2006.

"Progress versus Utopia; or, Can We Imagine the Future?" Science Fiction Studies XXVII/9-2 (1982).

Jenkins, Henry y Alicia Capel Tatjer. Piratas de textos: fans, cultura participativa y televisión. Barcelona: Paidós, 2010.

“"The Tomorrow That Never Was': Retrofuturism in the Comics of Dean Motter (Part One)". 18 junio 2007. $<\mathrm{http}: / /$ henryjenkins.org/2007/06/the_tomorrow_that never_was_re.html>. 1 abril 2013. 
“"The Tomorrow That Never Was': Retrofuturism in the Comics of Dean Motter (Part Two)". 19junio 2007.<http://henryjenkins.org/2007/06/the_tomorrow_that never_was_re_1.html>. 4 abril 2013.

"“The Tomorrow That Never Was': Retrofuturism in the Comics of Dean Motter (Part Three)". 19junio 2007.<http://henryjenkins.org/2007/06/the_tomorrow_that never_was_re_2.html>. 5 abril 2013.

Leal, Bruno; Carlos Mendonça, e César Guimarães. "Experiência Estética e comunicação: a partilha de um programa de pesquisa. Entre o sensível e o comunicacional. Belo Horizonte: Autêntica, 2010. 7-15.

Loja Paraná do Conselho Steampunk. "Carnivale SteamPunk - a primeira fotonovela brasileira SteamPunk”. <http://www.youtube.com/watch?v=Ehm8RJ8KVwo>. 20 dez. 2013.

"Carnivale SteamPunk - a primeira fotonovela brasileira SteamPunk. English version". <http://www.youtube.com/watch?v=_uzGAlQS-TU>. 20 dez. 2013.

e Full Steam - the Steampunk Group Campinas. "O Sequestro na Ferrovia". $<$ http://www.youtube.com/watch?v=diIhdiKJNaI\&feature=youtu.be $>.4$ fev. 2014.

Maffesoli, Michel. O Tempo das tribos. O declínio do individualismo nas sociedades de massa. Rio de Janeiro: Forense-Universitária, 1987.

Martins, Romeu. "Cidade Phantástica". Steampunk: Histórias de um passado extraordinário. Gianpaolo Celli, org. São Paulo: Tarja Editorial, 2009. 141-162.

Medeiros, Flávio. "Por um fio". Steampunk: Histórias de um passado extraordinário. Gianpaolo Celli, org. São Paulo: Tarja Editorial, 2009. 163-179.

Sennett, Richard. Carne e Pedra: o corpo e a cidade na civilização occidental. Rio de Janeiro: Editora Record, 2001.

Singer, Ben. "Modernidade, hiperestímulo e o início do sensacionalismo popular". $O$ cinema e a invenção da vida moderna. Leo Charney y Vanessa Schwartz, org. São Paulo: Cosac \& Naif, 2001.

Sodré, Muniz. "Eticidade, campo comunicacional e midiatização". Sociedade Midiatizada. Denis Moraes, org. Rio de Janeiro: Mauad X, 2006. 19-31.

Thornton, Sarah. Club Cultures: Music, Media, and Subcultural Capital. Cambridge: Polity, 1995.

Villa, Claudio. “O dobrão de prata”. Steampunk: Histórias de um passado extraordinário. Gianpaolo Celli, org. São Paulo: Tarja Editorial, 2009. 109-122. 
